\title{
Comparative Evaluation of Biochemical Effects of Date Palm (Phoenix dactylifera) Fruit Extracts on Paracetamol-induced Hepatotoxicity in Wistar rats
}

\author{
*IKPONMWOSA-EWEKA, O; EROMOSELE, AI
}

\author{
Department of Medical Biochemistry, College of Medical Sciences, University of Benin, Benin City, Edo State, Nigeria \\ *Corresponding author: omorede.aguebor@uniben.edu,Tel: +2348056679826
}

\begin{abstract}
The therapeutic activity of date palm extracts (Phoenix dactylifera) against paracetamol-induced hepatotoxicity was studied in rats of the Wistar strain. Forty-eight (48) Wistar rats were assigned into 8 groups equally. Group I (normal control) were given distilled water for 14 consecutive days. Group II (negative control) received paracetamol $(2 \mathrm{~g} / \mathrm{kg})$. Group III were pretreated with aqueous extract $(400 \mathrm{mg} / \mathrm{kg})$ for 7 days before receiving paracetamol $(2 \mathrm{~g} / \mathrm{kg})$ for 7 additional days. Group IV were pretreated with aqueous extract $(400 \mathrm{mg} / \mathrm{kg}$ ) for 7 consecutive days and paracetamol $(2 \mathrm{~g} / \mathrm{kg})$ for 7 additional days. Group V- received $2 \mathrm{~g} / \mathrm{kg}$ of paracetamol for 7 days and given $400 \mathrm{mg} / \mathrm{kg}$ aqueous extract for additional 7 days. Group VI received paracetamol $(2 \mathrm{~g} / \mathrm{kg})$ for 7 days followed by ethanolic extract $(400 \mathrm{mg} / \mathrm{kg})$ for 7 additional days. Group VII were co-administered paracetamol $(2 \mathrm{~g} / \mathrm{kg})$ and the aqueous extract $(400 \mathrm{mg} / \mathrm{kg})$ for 7 days. Group VIII were co-administered paracetamol $(2 \mathrm{~g} / \mathrm{kg})$ and ethanolic extract $(400 \mathrm{mg} / \mathrm{kg})$ for 7 days. To evaluate the efficacy of the extracts on paracetamol-compromised liver in Wistar rats, the enzyme activities of ALT, AST, ALP and bilirubin concentration in serum were investigated. Treatment with aqueous and ethanolic extracts at different timing significantly $(\mathrm{p}<0.05)$ decreased paracetamol-induced elevation of serum concentrations of ALT, AST and bilirubin. Concurrent administration of the extracts with paracetamol conferred better hepatoprotection compared to the prophylactic and curative treatments. The present findings suggest a potential therapeutic use of Phoenix dactyliferia in treatment of liver diseases.
\end{abstract}

DOI: https://dx.doi.org/10.4314/jasem.v23i4.11

Copyright: Copyright $\odot 2019$ Ikponmwosa-Eweka and Eromosele. This is an open access article distributed under the Creative Commons Attribution License (CCL), which permits unrestricted use, distribution, and reproduction in any medium, provided the original work is properly cited.

Dates: Received: 07 March 2019; Revised: 28 March 2019; Accepted 02 April 2019

Key words: Phoenix dactylifera, hepatoxicity, extract, paracetamol

Liver disease is a global health challenge which falls into two broad categories: acute and chronic. It is the $10^{\text {th }}$ leading cause of mortality in the US with an annual estimate of 25,000 deaths (Soleimanpour et al., 2015). In Africa, liver disorders are mainly caused by viral and parasitic infections, while in the Western hemisphere, alcohol abuse is the main cause (Muriel et al., 2008). Acetaminophen (APAP), an antipyretic and analgesic agent is generally known by its trade name paracetamol (Yoon et al., 2016). Acetaminophen overdose is the leading cause of acute liver failure in the Western world (Budnitz et al., 2011). Current prescription drugs for hepatic dysfunction have failed to deliver the expected health benefits to patients with liver issues. Thus, affected patients often resort to self-help with therapeutic modalities such as herbal formulations which are considered to be non-conventional (Seeff et al., 2001). The use of natural products dates back to antiquity appearing for the first time in historical accounts circa 600BC under the reign of the Xia dynasty in China and during the Vedic period in India (Radha et al., 2005). In recent decades, public use of herbal remedies for diseases including liver failure has gained increasing acceptance among people of various nationalities (Guan and He, 2013). Government surveys in Australia show that an estimated 42 percent of the population have at one time depended on alternative medicine for health restoration (Bensoussan, 1999).

Approximately, $80 \%$ of third world population relies on herbal formulations to meet their primary healthcare needs (Jimoh et al., 2013). Herbal medicine is believed to be better and safer than conventional therapeutic approaches owing to its easy availability, low costs, fewer side effects and natural healing (Astin, 1999). Sylimarin, an extract of milk thistle (Silybum marianum) is widely regarded as the most promising prospect among herbal products for the treatment of hepatotoxicity (Abenavoli et al., 2010) and the market share reaches up to 180 million dollars in Germany (Pradhan et al., 2006). Other plant-based products are being investigated for their hepatotherapeutic potential because nature is a rich source of innumerable amounts of phytochemicals that serve as potential precursors of novel therapeutic agents. Pharmacological screening of extracts composed of secondary metabolites is routinely 
performed in the early stages of development of plantbased drugs. Thus, the authors chose date palm (Phoenix dactylifera) for the study based on its folkloric use.

Phoenix dactylifera is a valuable crop that thrives in arid regions particularly the Middle East where the cultivation of the plant has spanned almost 6000 years (El Gazzar et al., 2009). The fruit which is composed of a fleshy pericarp and a seed forms an integral component of Middle Eastern diet. Date palm is used as a folklore remedy for sore throat, colds, bronchial obstruction, abdominal troubles and liver injury (Barh and Mazumdar, 2008). Biochemical studies have reported antioxidant, antihypertensive, antiinflammatory activities for the fruit extracts (AlShoaibi et al., 2012; Vayalil, 2012; Saafi et al., 2011; Mansouri et al., 2005). The study was undertaken to evaluate the efficacy of date palm extracts administered using pre-treatment, co-administration and post-treatment methods on adult wistar rats with paracetamol-induced liver failure.

\section{MATERIALS AND METHODS}

Preparation of plant extract: Fresh fruits of Phoenix dactylifera were collected, shade-dried and pound into fine powder. The aqueous extract was made by dissolving fifty (50) grams of the pulverized plant material in $1 \mathrm{~L}$ of distilled water for $72 \mathrm{~h}$ and regularly stirring the mixture at room temperature. To obtain the ethanol extract, two hundred (200) grams of Phoenix dactylifera was soaked in $2 \mathrm{~L}$ of absolute ethanol (95\%) at room temperature for $48 \mathrm{~h}$. The mixtures were filtered with Whatman filter paper and the filtrates concentrated under reduced pressure in a rotary evaporator at $40^{\circ} \mathrm{C}$. Reconstitution of extracts in water and ethanol to the desired concentrations was carried out and used for the experiment.

Experimental Animals: Forty-eight (48) Wistar rats weighing 100-140 g were obtained from Department of Physiology, School of Basic Medical Sciences, University of Benin, Nigeria. The animals had access to standard diet (pelletized guinea feed) and water $\mathrm{ad}$ libitum. They were acclimatized to the laboratory environment in the Department of Biochemistry, Faculty of Life Sciences, University of Benin, Nigeria for one week under standard conditions of temperature, relative humidity, and dark/light cycle.

Experimental Design: A total of forty eight (48) Wistar rats were assigned randomly into eight groups (six/group).

Group I - The normal control which was administered orally and daily an equivalent amount of distilled water (the vehicle) as other groups for 7 consecutive days

Group II - The negative control which was administered orally and daily $2 \mathrm{~g} / \mathrm{kg}$ of paracetamol for 7 consecutive days

Group III (prophylactic) - orally received P.dactylifera aqueous extract $(400 \mathrm{mg} / \mathrm{kg})$ for 7 consecutive days + paracetamol $(2 \mathrm{~g} / \mathrm{kg})$ for additional 7 days

Group IV (prophylactic) - orally received $P$. dactylifera ethanolic extract $(400 \mathrm{mg} / \mathrm{kg})$ for 7 consecutive days + paracetamol $(2 \mathrm{~g} / \mathrm{kg})$ for additional 7 days

Group V (ameliorative) - orally received paracetamol $(2 \mathrm{~g} / \mathrm{kg}$ ) for 7 consecutive days $+P$. dactylifera ethanolic extract $(400 \mathrm{mg} / \mathrm{kg})$ for additional 7 days

Group VI (ameliorative) - orally received paracetamol $(2 \mathrm{~g} / \mathrm{kg}$ ) for 7 consecutive days $+P$. dactylifera ethanolic extract $(400 \mathrm{mg} / \mathrm{kg})$ for additional 7 days

Group VII (protective) - was coadministered paracetamol $(2 \mathrm{~g} / \mathrm{kg})$ with $400 \mathrm{mg} / \mathrm{kg}$ of aqueous extract for 7 days

Group VIII (protective) - was coadministered paracetamol $(2 \mathrm{~g} / \mathrm{kg})$ with $400 \mathrm{mg} / \mathrm{kg}$ of ethanolic extract for 7 days

Blood Parameters: Blood was collected by cardiac puncture into plain containers and centrifuged for 15 $\mathrm{min}$ at $4000 \mathrm{rpm}$. The clear sera obtained was frozen at $-20 \mathrm{c}$ until it was analyzed for liver function parameters such as aspartate aminotransferase (AST), alanine aminotransferase (ALT) (Reitman and Frankel, 1957), alkaline phosphatase (TECO ALP kit) and bilirubin (Bartholomew and Delaney, 1966).

Statistical Analysis: Results are represented as means \pm standard error of mean (SEM). Differences between means were tested for significance using one-way analysis of variance (one-way ANOVA) and Duncan's post-hoc test. $\mathrm{P}$ values less than 0.05 were considered significant using statistical analytical software.

\section{RESULTS AND DISCUSSION}

Paracetamol - induced hepatotoxicity is the best studied and clinically important model for assessment of phytotherapeutics and other hepatoprotective modalities (Kuo et al., 2016). Cytochrome P450 2E1 mediated acetaminophen activation generates the highly reactive metabolite, NAPQ1 by a direct two electron oxidation of acetaminophen (Vermuelen et al., 1992). Recommended use of acetaminophen limits the production of NAPQI which is rapidly conjugated with glutathione for subsequent excretion. Excessive formation of NAPQI after accidental or intentional overdose of acetaminophen depletes available hepatic glutathione, then NAPQI binds freely with proteins 
causing necrosis and membrane damage. These processes inhibit glutathione dependent enzymes and liberate reactive oxygen species (ROS) into the cell. A novel Cytochrome P450- independent mechanism of paracetamol toxicity proposes that mitochondria are the main sources of ROS which downgrade mitochondrial function and uses signaling pathways to initiate necrotic cell death (Bansal et al., 2010). The Cytochrome P450-dependent mechanism hypothesizes that free radicals in excess amounts vigorously attack membrane polyunsaturated lipids resulting in lipid peroxidation and membrane damage. Furthermore, proteins and DNA undergo mutations and loss of biological activity upon interaction with these biological oxidants. When hepatocytes rupture under free radical onslaught, a variety of enzymes normally located in the cytosol are released into the bloodstream (Tezuka et al., 1995). The assessment of these enzymes in serum serves a valuable marker for the extent of hepatic failure.

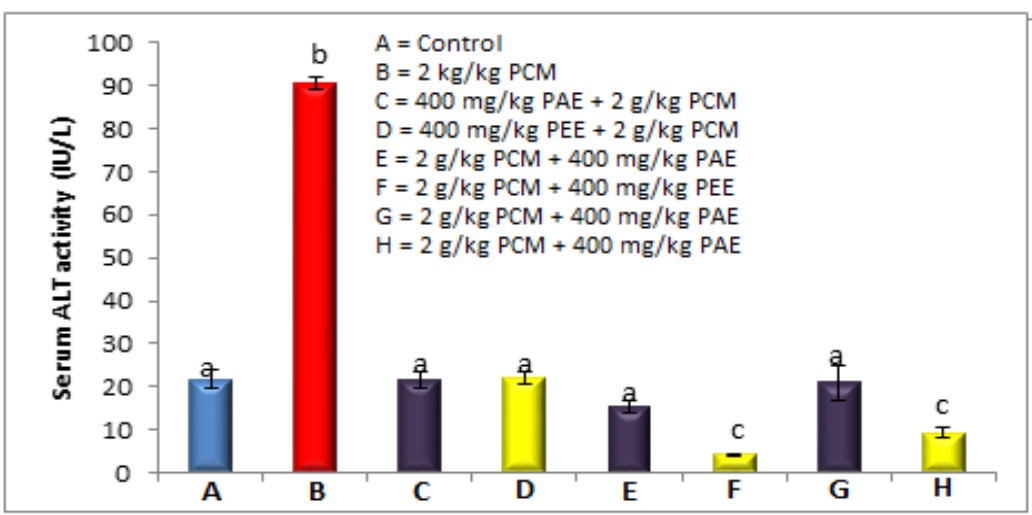

Fig 1: Effects of Phoenix dactylifera on ALT activity in paracetamol-intoxicated rats, $n=5$. Values are expressed as mean ALT activity $(1 \mathrm{U} / \mathrm{L}) \pm$ standard error of the mean. . Different superscripts represent significant difference $(\mathrm{p}<0.05)$ when compared with negative control (paracetamol group). Abbreviations: PAE, Phoenix dactylifera aqueous extract; PEE, Phoenix dactylifera ethanolic extract; PCM, paracetamol.

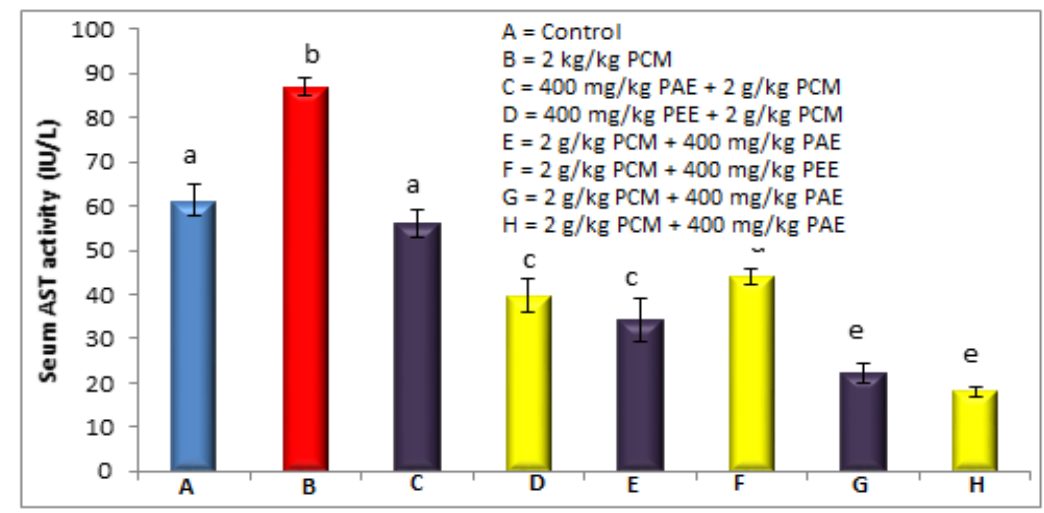

Fig 2: Effects of Phoenix dactylifera on AST activity in paracetamol-intoxicated rats, $\mathrm{n}=5$.Values are expressed as mean AST activity $(1 \mathrm{U} / \mathrm{L}) \pm$ standard error of the mean. Different superscripts represent significant difference $(\mathrm{p}<0.05)$ when compared with negative control (paracetamol group). Abbreviations: PAE, Phoenix dactylifera aqueous extract; PEE, Phoenix dactylifera ethanolic extract; PCM, paracetamol.

In the present study, hepatotoxicity was observed in rats treated with $2 \mathrm{~g} / \mathrm{kg} \mathrm{BW}$ of paracetamol and was reflected by the increase of serum ALT, AST and bilirubin as shown in Fig 1, 2 and 4 respectively. This is in agreement with Nzewi et al. (2016). The result in Fig. 1 revealed that pretreatment using ethanolic and aqueous extract lowered serum ALT levels to normal levels. Animals that received aqueous and ethanolic extracts after induction of hepatotoxicity had the lowest ALT activity. There was no significant difference $(\mathrm{p}<0.05)$ between the ALT activities of rats fed with ethanol and aqueous extracts in the pretreatment and post-treatment groups. AST and ALT are the most important biomarkers for liver membrane disruption because their concentrations in serum correlate with the extent of hepatic damage (Ansari et al., 1991). However, ALT is the more specific and reliable marker for liver damage because its concentration is only elevated in liver disease. In contrast, AST can give false positive results since other diseases such as hepatitis, muscle injury, myocardial infarction could contribute to a rise in its 
concentration (Asadollahi et al., 2014). As shown in Fig. 2, groups that were given only paracetamol demonstrated elevated serum AST levels comparable to those that received distilled water (normal control). Prophylactic or ameliorative treatments decreased the concentration of AST in serum in comparison to the positive control group whereas curative therapy demonstrated the steepest decline in AST activity. The aqueous and ethanolic extracts of $P$. dactylifera induced therapeutic responses in the animals with paracetamol-induced liver disease by causing a dramatic reduction of AST and ALT levels in serum of the animals. Date palm -induced decline of AST and ALT levels in serum has also been reported in related studies in which carbon-tetrachloride induced hepatotoxicity in dogs and rabbits (Abdelrahman et al., 2012; Usama et al., 1990).

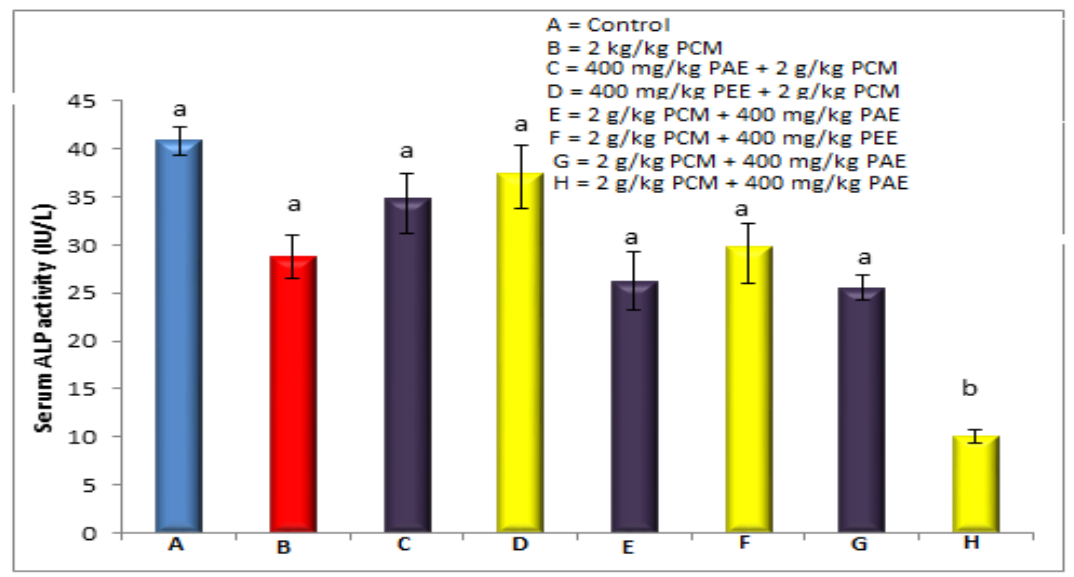

Fig 3: Effects of Phoenix dactylifera on ALP activity in paracetamol-intoxicated rats, $n=5$. Values are expressed as mean ALP activity $(1 \mathrm{U} / \mathrm{L}) \pm$ standard error of the mean. Different superscripts represent significant difference $(\mathrm{p}<0.05)$ when compared with negative control (paracetamol group). Abbreviations: PAE, Phoenix dactylifera aqueous extract; PEE, Phoenix dactylifera ethanolic extract; PCM, paracetamol.

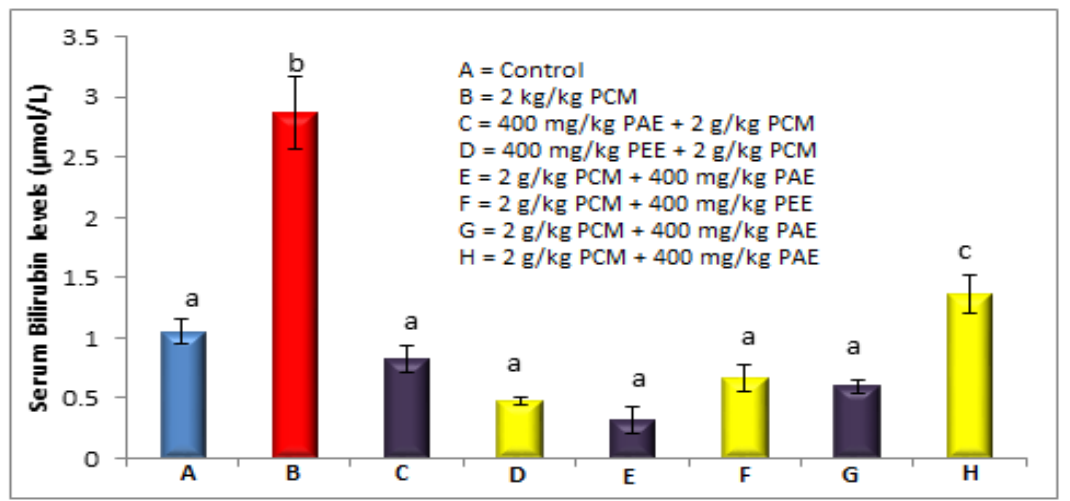

Fig 4: Effects of Phoenix dactylifera on serum bilirubin concentration $(\mu \mathrm{mol} / \mathrm{L})$ in paracetamol-intoxicated rats, $\mathrm{n}=5$.Values are expressed as mean bilirubin concentration $(1 \mathrm{U} / \mathrm{L}) \pm$ standard error of the mean. Different superscripts represent significant difference $(\mathrm{p}<0.05)$ when compared with negative control (paracetamol group). Abbreviations: PAE, Phoenix dactylifera aqueous extract; PEE, Phoenix dactylifera ethanolic extract; PCM, paracetamol

Although paracetamol induces high alkaline phosphatase activity in rats as reported by Eyong et al. (2017), the serum level of this enzyme did not change significantly after oral exposure to paracetamol as shown in Fig. 3. Experimental error may be the possible explanation for this unusual occurrence. The aromatase activity of CYP 450 is inhibited by Vit C in experimental guinea pigs and may explain why date palm which has appreciable quantity of Vit C possesses chemoprotective activity against hepatocellular injury (Kowalska, 1990). The scavenging activity of $\beta$-sistosterol, a constituent of Phoenix dactylifera against NAPQI and mitochondrial generated reactive oxygen species may explain the observed therapeutic effects of the plant extracts on serum aminotransferases (Kuo et al., 2016; Okwuosa et al., 2014). Also, the relatively significant vitamin C content, a potent scavenger of biological oxidants in Phoenix dactylifera could explain the membrane sealing property of the extracts. It might be argued that factors other than vitamin $\mathrm{C}$ content may have attenuated NAPQI toxicity. 
Serum bilirubin estimation serves as a parametric indicator for the binding, conjugation and excretory capacity and severity of necrosis of hepatocytes (Oboh, 2005). According to the data presented in Fig. 4 , oral administration of $P$. dactylifera extracts by using different therapeutic approaches to rats alleviated hepatotoxicity in wistar rats by inducing a steep decline of serum bilirubin concentration. Significant difference $(\mathrm{p}<0.05)$ in serum bilirubin levels were not observed among the groups that were treated with extracts. To account for the relatively high serum bilirubin in paracetamol intoxicated rats, the possible explanation may be that centrilobular necrosis and extensive liver membrane disruption might have occurred in response to rapid binding of NAPQI to tissue protein leading to uncontrolled secretion of bilirubin into the bloodstream (Boyd and Bereczsky 1996). The administration of extracts to the experimental models of liver injury significantly $(\mathrm{p}<0.05)$ lowered serum bilirubin of the test animals compared to the positive control. Bilirubin concentration in animals did not vary significantly among the groups served with extracts at different time measured from the point of paracetamol intoxication. Flavonoids present in date palm are powerful antioxidants that may act as membrane stabilizers for hepatocytes (Etuk et al., 2009). These may have caused the decline in bilirubin concentration. Based on the preceding observations, it can be inferred that hyperbilirubinaemia and jaundice could be ameliorated by oral consumption of the plant (Nzewi et al., 2016). All treatment with extracts caused rat hepatocytes to recover from the adverse effects of paracetamol overdose implying that date palm has prophylactic, ameliorative and curative potentials for hepatic disorders.

Conclusion: Overall, concurrent administration of extracts and paracetamol seemed to offer slightly better defence against paracetamol-induced hepatotoxicity than pretreatment and post-treatment with extracts. We recommend the incorporation of date fruit into the Nigerian dietary regimen for proper maintenance of the liver in excellent conditions. Further investigation is required for isolation and characterization of hepatoprotective constituents in Phoenix dactyliferia.

\section{REFERENCES}

Abdelrahman, H A; Fathalla, S I; Mohamed, AA; Jun, H K; Kim, D.H (2012). Protective Effect of Dates (Phoenix dactylifera L.) And Licorice (Glycyrrhiza glabra) on Carbon TetrachlorideInduced Hepatotoxicity in Dogs. Global Veterinaria. 9 (2): 184-191
Abenavoli, L; Capasso, R; Millic, N; Capasso, F (2010). Milk thistle in liver diseases: past, present and future. Phytother. Res. 24(10): 1423-32

Al-Shoabi, Z; Al-Mamary, M A; Al-Habor, M.A; AlZubairi, A S; Abdelwahab, S I (2012). In vivo antioxidative and hepatoprotective effects of palm date fruits (Phoenix dactylifera). Inter. J. Pharmacol. 8: 85-191

Ansari, R A; Tripathi, S C; Patnaik, G K; Dhawan, B N (1991). Antihepatotoxic properties of picro liv, and active fraction from rhizomes of Picrorhiza kurroa. J. Ethnopharmacol. 34: 61-68

Asadollahi, A; Sarir, H; Omidi, A; Mohammad, B M T (2014). Hepatoprotective Potential of Prosopis farcta Beans Extracts against Acetaminopheninduced Hepatotoxicity in Wister Rats. Inter. J. Prev. Med. 5(10): 1281-1285

Astin, JA (1991). "Why patients use alternative medicine: results of a national study". J. Amer. Med. Assoc. 279 (19):1548-1553

Bansal, S; Liu, C P; Sepuri, N B; Selvaraj, V; Hoek, J; Milne, G L; Guengerich, F P; Avadhani, N G (2010). Mitochondria-targeted cytochrome P450 2E1 induces oxidative damage and augments alcohol mediated oxidative stress. J. Biol Chem. 285:24609-24619

Barh, D; Mazumdar, B.C (2008). Comparative traditional medicine of the nutritive values of palm saps before and after their partial fermentation and effective use of wild date (Phoenix sylvestris Roxb.) Sap in treatment of anemia. Res. J. Medicine. Med. Sci. 3: 173-176

Bensoussan, A (1999). Complementary MedicineWhere lies its appeal? Med J Aust.170:247-248.

Budnitz, D S; Lovegrove, M C ; Crosby, A E (2011) Emergency Department visits for overdoses of acetaminophen-containing products. Am. J. Prev. Med. 40:585-592

El-Gazzar, U B; El-Far, A H.; Abdel-Maksoud, H A (2009). The Ameliorative Effect of Phoenix dactylifera extract on $\mathrm{CCl}_{4}$ Hepatotoxicity. J. Appl. Sci. Res. 5(9): 1082-1087

Etuk, E U ;Agaie, B M; Ladan, M J; Garba, I (2009) The modulatory effect of Cochlospermum tinctorium a rich aqueous root extract on liver 
damage induced by carbon tetrachloride in rats. Afr J Pharm Pharmacol.3:151-7

Eyong, U E; Egbung, G E; Ndiodimma, V N (2017). Amelioration potentials of Vernonia calvaona ethanol leaf extract in paracetamol-treated rats $J$. Pharmacognosy Phytotherapy. 10(1):1-10

Jimoh, AO; Sani, Z; Abubakar, K; Mshelia, HE (2013). Safety Concerns and Determinants of Complementary Alternative Medicine Use in a Sub-Urban area of Sokoto, North Western Nigeria. J. Med. Sci. 13(8):737-742

Kowalska, MT; Brandt, ME; Puett, D (1990) "Inhibition of cytochrome p 450 aromatase activity by plant extracts". Planta Medica. 56:675-677

Kuo, D; Anup, R; Hartmut, J (2016). Oxidative stress during acetaminophen hepatotoxicity: Sources, pathophysiological role and therapeutic potential. Redox Biol.10:148-156

Malloy, H T; Evelyn, K A (1937). Determination of bilirubin with the photometric colorimeter. J. Biol Chem. 119:481

Mansouri, A; Embarek, G; Kokkalou, E; Kefalas P (2005). Phenolic profile and antioxidant activity of the Algerian ripe date palm fruit (Phoenix dactyliferia L.). Food Chem. 89:411-420.2005

Muriel, P; Rivera-Espinoza Y (2008). Beneficial drugs for liver diseases. J. Appl. Toxicol. 28:93-103

Nzewi, J I; Okojie, K A; Edoga, C O; Sobanke, O A; Nwobodo, E (2016). Effect of Methanolic Extract of Emilia Praetemissa on Paracetamol Induced Liver Damage in Albino Wistar Rats. J. Pharm. Biol. Sci. 11(6): 29-36

Oboh, G (2005). Hepatoprotective property of ethanolic and aqueous extracts of fluted pumpkin (Telfairia occidentalis) leaves against garlicinduced oxidative stress. J. Med. Food. 8: 560563

Okwuosa, CN; Udeani TK; Umeifekwem, JE; Onuba, AC; Anioke, IC; Madubueze, RE (2014) Hepatoprotective effect of methanolic fruit extracts of Phoenix dactyliferia (Arecaceae) on thioacetamide induced liver damage in rats. Am J. Phytomed. Clinic. Therapeut. 2(3): 290-300
Radha, K D; Yogesh, K C (2005). Herbal medicine for liver diseases. Digestive Diseases and Sciences. 50(10):1807-1812

Reitman, S; Frankel, S (1957). A method of assaying liver enzymes in human serum. Amer. J. Clinic. Pathol. 28:56-58

Saafi, E B; Louedi, M; Elfeki, A; Zakhama, A; Najjar, M F; Hammami, M; Achour, L.(2011).Protective effects of date palm fruits extract (Phoenix dactyliferia $L$ ) on dimethoxate induced oxidative stress in rat liver. Experimental Toxicol. Pathology.63: 433-441

Seeff, LB; Lindsay, KL; Bacon, BR (2001). Complementary and Alternative Medicine in chronic liver disease. Hepatology. 34:595-603.

Soleimanpour, H. Safari, S., Rahmani, F., Ameli, H., Alavian, S.M (2015). The Role of Inhalational Anesthetic Drugs in Patients with Hepatic Dysfunction: A Review Article. Anesthesiology and Pain Medicine. 5 (1)23409

Tezuka, M S; Sadanobu, K; Gomi, T; Sawamura, R (1995). In vitro effect of chromium and other trace metals on mouse hepatotoxicity induced by carbon tetrachloride exposure. Bio. Pharm Bull.8: 256-261

Usama, B E; Ali, H E; Hussein, AA (2009) .The Ameliorative Effect of Phoenix Dactylifera Extract on $\mathrm{CCl} 4$ Hepatotoxicity in New Zealand Rabbits. J. Appl. Sci. Res. 5(9): 1082-1087

Vayalil, P K (2012). Date fruits (Phoenix dactyliferia Linn): An emerging medicinal food. Critical Reviews in Food Science and Nutrition. 52:249271.

Vermuelen, NPE; Bessems, JGM; Van De Street, R (1992). Molecular aspects of paracetamol induced hepatoxicity and its mechanism based prevention. Drug Metab Rev.24: 367.1992

Yoon, E; Babbar, A; Choudhary, M; Kutner, M; Pyrsopoulos, N 2016).Acetaminophen-Induced Hepatoxicity: A Comprehensive Update. J. Clinic. Translational Hepatology. 4(2):131-142 